\title{
BMJ Open Greenness and job-related chronic stress in young adults: a prospective cohort study in Germany
}

\author{
Ronald Herrera, ${ }^{1,2}$ lana Markevych,,4,5 Ursula Berger, ${ }^{2}$ Jon Genuneit, ${ }^{6}$ \\ Jessica Gerlich, ${ }^{1}$ Dennis Nowak, ${ }^{4,7}$ Wolff Schlotz, ${ }^{8}$ Christian Vogelberg, ${ }^{9}$ \\ Erika von Mutius, ${ }^{4,10}$ Gudrun Weinmayr, ${ }^{6}$ Doris Windstetter, ${ }^{1}$ Matthias Weigl, ${ }^{7,11}$ \\ Joachim Heinrich, ${ }^{1,4}$ Katja Radon ${ }^{1,11}$
}

To cite: Herrera R, Markevych I, Berger U, et al. Greenness and job-related chronic stress in young adults: a prospective cohort study in Germany. BMJ Open 2018;8:e21599. doi:10.1136/ bmjopen-2018-021599

- Prepublication history and additional material for this paper are available online. To view these files, please visit the journal online (http://dx.doi. org/10.1136/bmjopen-2018021599).

Received 10 January 2018 Revised 7 March 2018 Accepted 17 April 2018
Check for updates

For numbered affiliations see end of article.

Correspondence to

Ronald Herrera;

rherrera@med.Imu.de

\section{ABSTRACT}

Objectives We aimed to prospectively study the association between normalised difference vegetation index (NDVI) as a measure of greenness around homes and occupational stress.

Setting A population-based cohort in Munich and Dresden cities was followed from age $16-18$ years to age $20-23$ years $(n=1632)$.

Participants At baseline, all participants attended highschool while at follow-up some had started working and others studying at university. At baseline and in each follow-up, we assigned NDVI based on participants' residential geocoded addresses and categorised it by quartiles.

Outcome measures School-related, university-related or job-related self-reported chronic stress was assessed at the two follow-ups by the Trier Scale for Assessment of Chronic Stress using work discontent and work overload as outcomes. We modelled the association employing ordinal generalised estimating equations model accounting for changes in sociodemographics, non-job-related stress, job history and environmental covariates. Stratified analysis by each city was performed.

Results NVDI at baseline was higher for participants from Dresden (median=0.36; IQR 0.31-0.41) than Munich $(0.31 ; 0.26-0.34)$. At follow-up, it decreased only for participants in Dresden $(0.34 ; 0.30-0.40)$. Higher greenness (quartile 4 vs quartile 1) was associated with less work discontent (OR $0.89 ; 95 \% \mathrm{Cl} 0.80$ to 0.99 ) and less work overload (OR $0.87 ; 95 \% \mathrm{Cl} 0.78$ to 0.96 ). In stratified analyses, results were more consistent for Munich than for Dresden.

Conclusions Our results suggest that residential green spaces, using the vegetation index as a proxy for exposure, are inversely associated with two types of job-related chronic stress in German young adults transitioning from school to university or working life.

\section{INTRODUCTION}

Some projections estimate that around $66 \%$ of the worldwide population is expected to live in urban areas by 2060; in Germany, this proportion is expected to reach $92 \%$ by then. ${ }^{1}$ Moreover, the global number of large
Strengths and limitations of this study

- This paper is the first study investigating the association of greenness and job-related chronic stress using a prospective study in young adults.

- We used a validated instrument to measure the job-related stress as well as stress dimensions outside the workplace.

- Our results remained robust when controlling for a wide range of confounding factors like sociodemographic variables, type of employment and non-job-related chronic stress.

- We used satellite images from 2009 for the normalised difference vegetation index calculations, which were not temporally aligned with the survey used.

- We did not include participants' commuting times, nor green measurements at work places, making it impossible to control for these covariates.

- Some contextual data like ethnic background and social cohesion were not taken into account in our analysis.

cities (ie, 5-10 million inhabitants) will be 65 by the year of 2030, housing approximately 400 million people worldwide. ${ }^{2}$ Large cities present advantages for economic growth and industrialisation. Also, they promote livability and sustainability and are bringing social and health benefits. ${ }^{3}$ However, big cities have adverse impacts on health and well-being of their inhabitants. ${ }^{4}$

Mental health is especially affected in big cities, in part because of reduction of social interaction, excessive commuting and through increments in psychological stressors. ${ }^{5}{ }^{6}$ Psychological distress has been identified as an essential public health and economic problem in large cities because it leads to work absence, lower productivity or early retirement. ${ }^{7}$ Susceptible populations like students and young adults in transition from school to job/university life reported 
increments in job-related chronic stress. ${ }^{8}$ In line with this, evidence has shown significant mental health benefits of residing in cities with more natural environments through restorative effects on psychological health. ${ }^{9-17}$

Mechanisms explaining the restorative effect of a green environment are attributed mainly to physical activity, social contact and deliberately seeking environments to recover from demanding situations and tasks. ${ }^{10} 12$ 18-21 Restorative niches were associated with emotional wellbeing, as well as increments of project management capabilities in adolescents transitioning from junior to secondary school. ${ }^{22}$ Additionally, few studies have studied associations between the access to green environments and job satisfaction. ${ }^{23-25}$ Researchers have shown the restorative effect of greenness mainly at schools or workplaces. ${ }^{196-28}$ These studies showed that being exposed to a green environment at the workplace/school is beneficial for workers or students. Despite these potential benefits, most of the office workers and students do not go outdoors during the job/study day, mainly because of a perception of having many tasks to do and a job/studying culture that does not include outdoor behaving. ${ }^{27} 29$

So far, there are few studies relating greenness around the home environment to job-related chronic stress, especially in longitudinal settings. ${ }^{163031}$ No previous research has analysed the association between greenness at home and job-related stress development in young people in the transition from school to university or working life. Our aim was therefore to investigate the association between normalised difference vegetation index (NDVI) as a measure of greenness around homes and two different job/study-related chronic stress measurements: work discontent and work overload. ${ }^{32} 33$ Data were drawn from a population-based cohort in two major German cities, specifically Munich and Dresden, surveying young adults in the transition from high school to university or working life.

\section{METHODS}

We analysed data of the SOLAR (Studie in Ost- und Westdeutschland zu beruflichen Allergierisiken) I and SOLAR II studies. ${ }^{34}$ These studies were aimed at studying the course of respiratory diseases and atopy in symptomatic and non-symptomatic children and young adults. Also, occupational risk factors were assessed to investigate associations among occupational factors, stress and the course of respiratory diseases. SOLAR II is the second follow-up of the German phase II of the International Study on Asthma and Allergies in Childhood (ISAAC II), a multicentre study planned to assess the prevalence of asthma and allergies with participants from elementary school students. ${ }^{35}$ The German branch of the ISAAC II was carried out in 1996/1997 in Munich and Dresden. In these cities, it included 7498 participants at age 10 years (fourth grade, age range 9-11 years). From August to January 2003, 3053 of these participants answered the questionnaire of the first follow-up of the study (SOLAR
I; age range 16-18 years). From August 2007 to November 2008, 2051 of the participants agreed to participate in SOLAR II (age range 19-24 years).

In the present analysis, we considered questionnaire data from SOLAR I and II, as only these two surveys contained data on chronic stress (figure 1). Besides chronic stress items, the written questionnaires contained validated items on sociodemographics, type of job, occupational diseases and physical activity. More details on the study methods are given by Heinrich et al. ${ }^{34}$

In the current analyses, we excluded participants who had ever worked before SOLAR I $(n=318)$, those without information on educational status $(n=21)$ and those with more than two items missing in one of the Trier Inventory for Chronic Stress (TICS) ${ }^{32} 33$ scales $(n=24)$. We geocoded the families' or participants' most recent addresses in SOLAR I and SOLAR II. We then calculated the environmental covariates and matched them to the individual questionnaire information. We excluded 56 participants because they moved out of the study areas (figure 1).

All participants or their legal guardians provided written informed consent.

\section{Variable definition}

Job-related stress

For this study, it was essential to use an instrument applicable to the school, university and working environments. TICS is a well-established instrument that includes scales of job-related chronic stress and stress outside the workplace dimensions. These scales were selected using the model of health ${ }^{33}$ and validated using confirmatory analysis in a representative sample. ${ }^{32}$ Hence, it is well suited to study the change of stress from school life to working or university life. We used two job-related TICS subscales as chronic stress outcomes: work discontent (eg, "Satisfaction from the work that I have to perform daily") and work overload (eg, "Too little time to execute my daily tasks"). Responses were assessed on a 5-point Likert scale from 'never' ( 0 points) to 'very often' ( 4 points). Total scores were formed as sum of all particular items in each subscale. Based on the recommendations of the scales' authors, ${ }^{33}$ up to two missing items per subscale were accepted otherwise, the subscale was considered as missing. Each subscale was categorised based on the frequency of stressful situations, as 'low' ( $\leq$ median), 'average' (above median to median $+1 \mathrm{SD}$ ) and 'high' $\left(\geq 1 \mathrm{SD}\right.$ from the median). ${ }^{36}$ We used the median and SD obtained in SOLAR I to categorise the outcomes in SOLAR I and SOLAR II.

\section{Greenness of the home environment}

We geocoded participants' addresses in SOLAR I and SOLAR II. Based on the geocoding, the exposure to natural and green areas around each home address was estimated using NDVI, a satellite image-based vegetation index. $N D V I=\frac{N I R-R R}{N I R+R R}$ is the ratio of differences between the near-infrared region (NIR) and red reflectance (RR) to the sum of these two measures, and it ranges between 


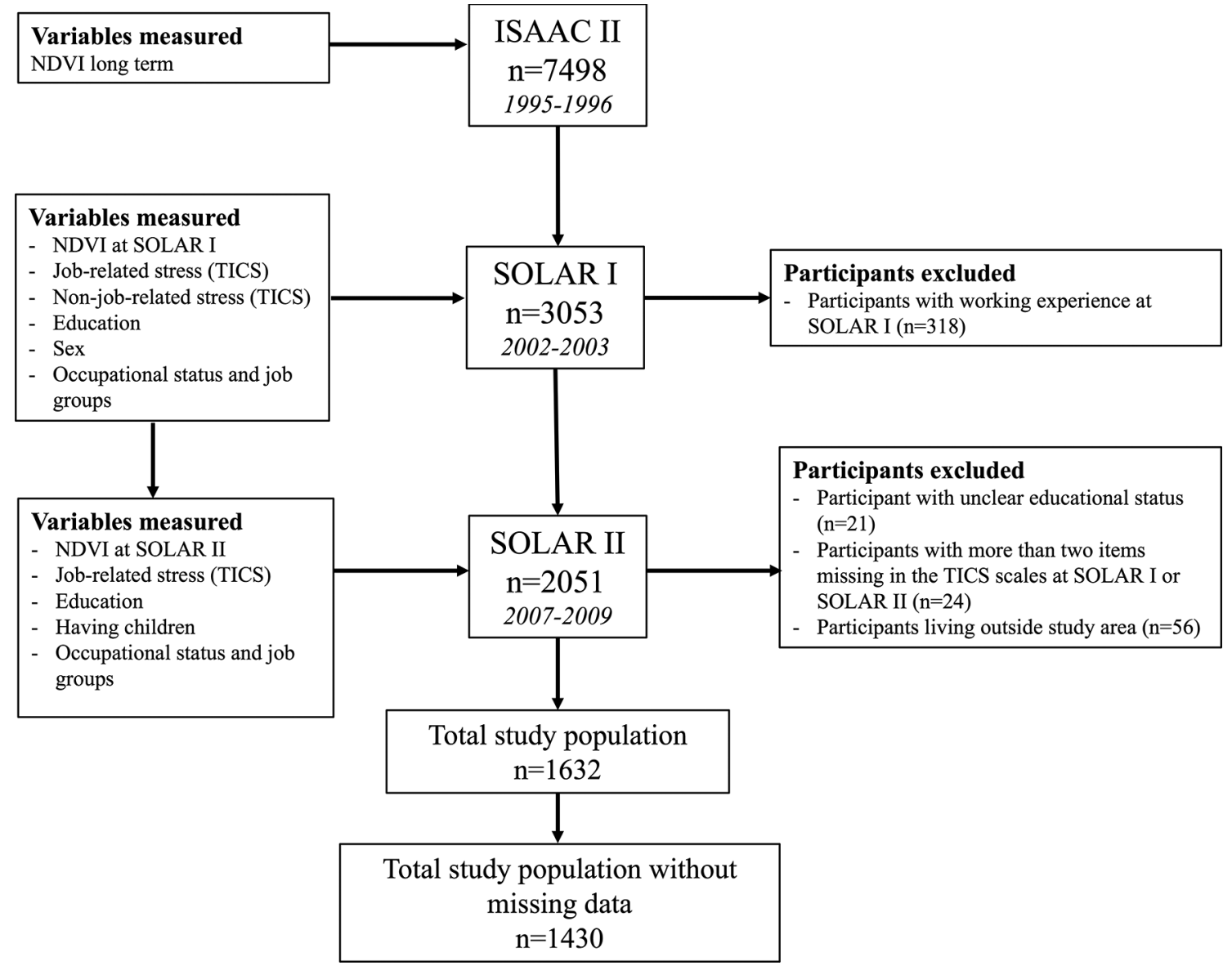

Figure 1 Flow chart of follow-up from International Study on Asthma and Allergies in Childhood (ISAAC) phase II to SOLAR II including normalised difference vegetation index (NDVI) measurements, job-related and non-job-related stress variables and total participants in each follow-up and the current analysis. Excluded participants: $n=318$ ever worked previously to SOLAR I, $\mathrm{n}=21 \mathrm{no}$ educational status information, $\mathrm{n}=24$ more than two Trier Scale for Assessment of Chronic Stress (TICS) items missing and $n=56$ residence out of the study areas.

-1.0 (water) and 1.0 (dense green vegetation), with zero indicating sand, snow or rocks. ${ }^{37}$ Choosing Landsat 5 Thematic Mapper (http://earthexplorer.usgs.gov/) cloud-free satellite images, an average NDVI was obtained using a $30 \mathrm{~m}$ by $30 \mathrm{~m}$ resolution in a $500 \mathrm{~m}$ radius around home addresses. The $500 \mathrm{~m}$ radius was used because it is considered to reflect better greenness directly accessible outside each home. ${ }^{38}$ For the Munich area (including the city of Munich and an adjacent region of Upper Bavaria), we used two images from 31 August in 2009 and merged them to cover the entire study area. In Dresden (including the Saxony area), four images were combined to cover the study area. As no data for a single day were available, we used images from 24 and 31 August in 2009. Finally, the exposure was categorised using survey and city-specific quartiles to account for distributional differences between city and study period. ${ }^{39}$

\section{Covariates}

Sociodemographics

As sociodemographic variables, we included: sex (male vs female), highest educational status reported at SOLAR I and SOLAR II (elementary education vs secondary education, advanced technical or higher education) and if the participant had children by SOLAR II (no vs yes). To account for physical activity, we used the WHO recommendations ${ }^{40}$ considering the age-specific cut-o $\square$ point for SOLAR I ( $\geq 4$ hours/week) and SOLAR II ( $\geq 2$ hours/ week).

\section{Non-job-related chronic stress}

TICS also measures the stress outside the workplace/ university environment using the following four subscales:

- social overload (eg, "I quarrel with others because I do not behave the way others expect me to");

- lack of social recognition (eg, "The experience that other people have no trust in me");

- chronic worrying (eg, "Times when I am not able to suppress my worries");

- stressful memories (eg, "Recurrent memories of failures").

We measured these non-job-related chronic stress scales in SOLAR I only (figure 1) because they are considered to be persistent over time ${ }^{8}$ and used them as covariates to control for self-perceived stressful circumstances outside the work or study environment. Categorisation of the 
non-job-related chronic stress scales was done using the same method as for job-related stress.

\section{Current status and job type}

At SOLAR II, we categorised the occupational status as follows: employee (reference), university student, vocational trainee (in a dual training programme), unemployed, self-employed and other (ie, on maternity leave or being work disabled). ${ }^{8}{ }^{34}$ In addition, participants reported any jobs they had ever held up until SOLAR I and between SOLAR I and SOLAR II. Two trained persons coded these jobs (including regular employment, student job or internship) according to the International Standard Classification of Occupations (ISCO-88) ${ }^{41}$ Following the ISCO classification, we assigned each working participant to one of five job groups: clerks, professionals and technicians, healthcare professionals (ie, with direct patient contact), plant machine operators and elementary occupations (ie, routine tasks using mainly handheld tools and some involving physical effort).

\section{Environmental covariates}

We used the European Environmental Agency databases ${ }^{42}$ to link participants' residential addresses to the following spatial covariates: distance to sports facilities, ${ }^{43}$ distance to nearest urban green space ${ }^{44}$ (ie, either a garden, a park, a cemetery or a plant nursery), distance to nearest lake or river ${ }^{11}$ and the percentage of tree coverage ${ }^{45}$ (ie, the percentage of flat ground covered by woody vegetation over a $5 \mathrm{~m}$ height). Additionally, we included the proportion of soil sealing derived in $2000 \mathrm{~m}$ buffer for the year 2009 as a measure of urbanisation degree. Finally, we used the NDVI measurement in a $500 \mathrm{~m}$ buffer at ISAAC II as a continuous variable to control for long-term greenness exposure. ${ }^{42}$

\section{Statistical analysis}

We employed generalised estimating equations (GEE) models for ordinal outcomes with an exchangeability correlation structure. ${ }^{46}$ Applying this strategy, we assessed the relationship between greenness and job-related stress, meanwhile controlling for the outcomes temporal correlation. ${ }^{46} 47$ GEE methods produce population-averaged estimates, that is, they describe changes in the population mean based on changes in covariates. ${ }^{47} 48 \mathrm{In}$ the present analysis, GEE estimates tell us how much the studied outcomes (work overload or work discontent) would change on average in the population for each NDVI quartile increase controlling for covariates. Positive values thus mean an increase in chronic stress over time.

We included all mentioned covariates in the final models. Given the possible interaction between city and greenness, ${ }^{39}$ we stratified the analyses by city (Munich and Dresden). Furthermore, we estimated the final models using only participants who never changed their home addresses during the whole study period $(n=675)$. Additionally, we restricted the analyses to only students $(\mathrm{n}=845)$ and only workers, that is, participants that reported being employees or vocational trainees $(n=670)$.
Finally, we performed a mediation analysis using the approach suggested by Schluchter ${ }^{49}$ to test the hypothesis that physical activity could mediate the association between greenness and job-related stress.

Using complete-case analyses in the presence of missing data might bias the results. ${ }^{50}$ Therefore, we constructed five imputed datasets using multiple imputations by chained equations. ${ }^{51}$ Using Rubin's rules, ${ }^{52}$ we obtained the combined adjusted ORs and CIs. We presented the comparison between complete cases and multiply-imputed estimates in the online supplementary material.

Statistical analyses were performed in R V.3.3.1 ${ }^{53}$ and the geographical calculations using ArcGIS 10.0 (Environmental Systems Research Institute, 2012) joint with the Geospatial Modelling Environment software (Spatial Ecology).

\section{Patient and public involvement}

Patients and public were not involved in the design of the study.

\section{RESULTS}

The number of participants in both cities was similar (869 in Munich and 763 in Dresden). Surrounding average greenness in a $500 \mathrm{~m}$ buffer for SOLAR I was higher in Dresden (median=0.36; IQR 0.31-0.41) than Munich (0.31; IQR 0.26-0.34). In SOLAR II, NVDI decreased for participants in Dresden (0.34; IQR 0.30-0.40) while it remained the same for participants living in Munich (0.31; IQR 0.260.34) (see online supplementary table $\mathrm{S} 1$ and figure $\mathrm{S} 1$ ).

Comparing the covariates across the greenness quartiles, we found small difference between quartiles (table 1): participants with children tended to live in places with greenness values in the lower quartiles of the greenness distribution, and those with higher education and students in the upper quartiles. Likewise, the percentage of physically active people was higher with increasing level of greenness around the participants' houses. Based on the $p$ values, we did not find statistically significant differences in Munich between the distance to sports facilities or distance to the nearest urban green space and NDVI quartiles; however, all other environmental covariates showed statistically significant differences with respect to NDVI quartiles. In Dresden, all environmental covariates were associated with NDVI (table 1).

Prevalence of high levels of work discontent and work overload decreased by increasing level of greenness in a buffer of $500 \mathrm{~m}$ around the home, especially for SOLAR II (table 2). Results were confirmed when we took changes over time into account as shown by ORs $<1$ for work discontent (adjusted OR comparing the fourth to the first quartile of greenness: OR 0.89 ; $95 \%$ CI 0.80 to 0.99 ) and work overload (OR 0.87; 95\% CI 0.78 to 0.96) (figure $2 \mathrm{~A}$ ).

Restricting the study population to participants who did not move between ISAAC II and SOLAR II did not affect the results (figure 2B). Stratifying by city, results were more consistent for Munich than for Dresden. In 


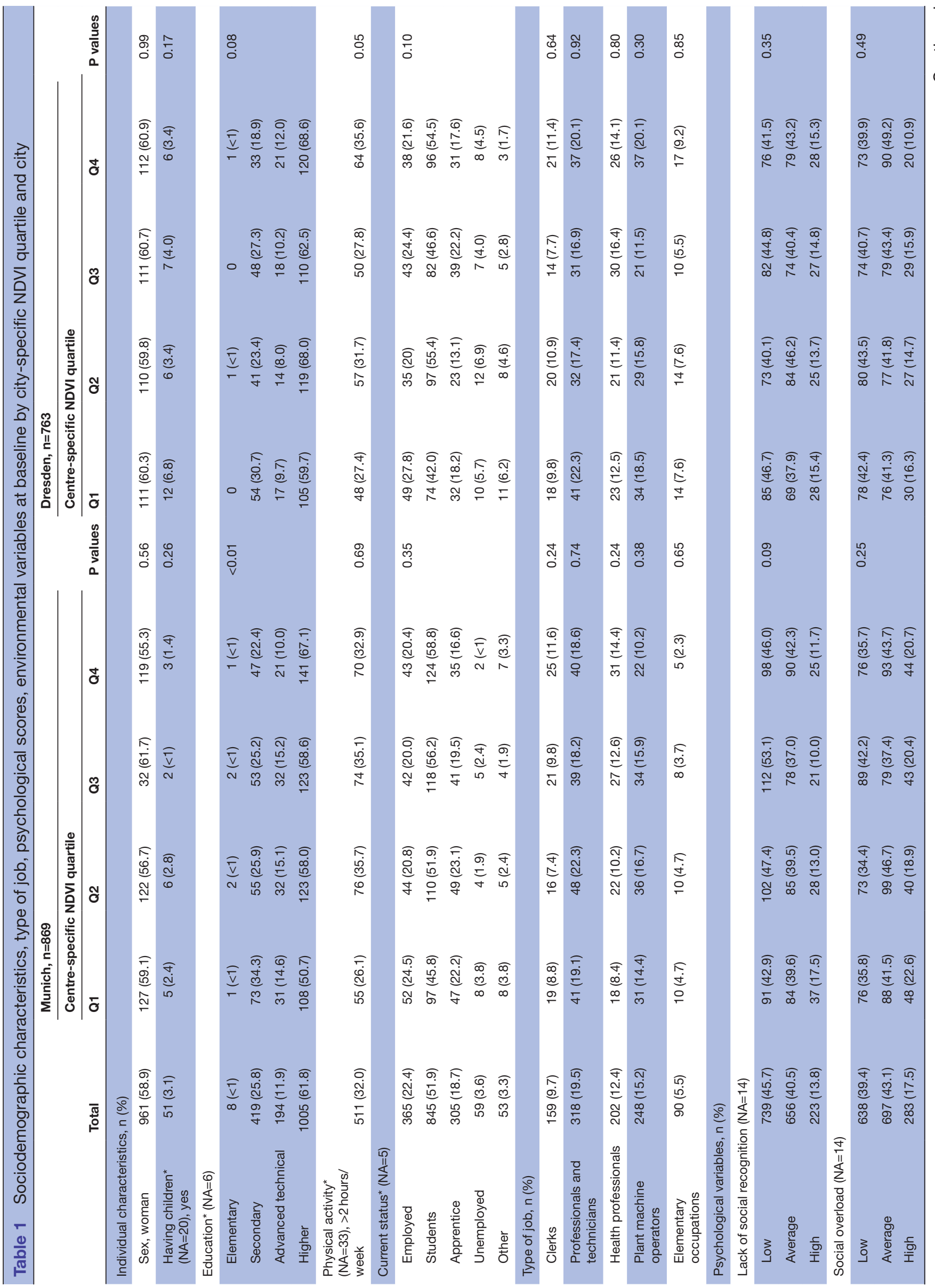




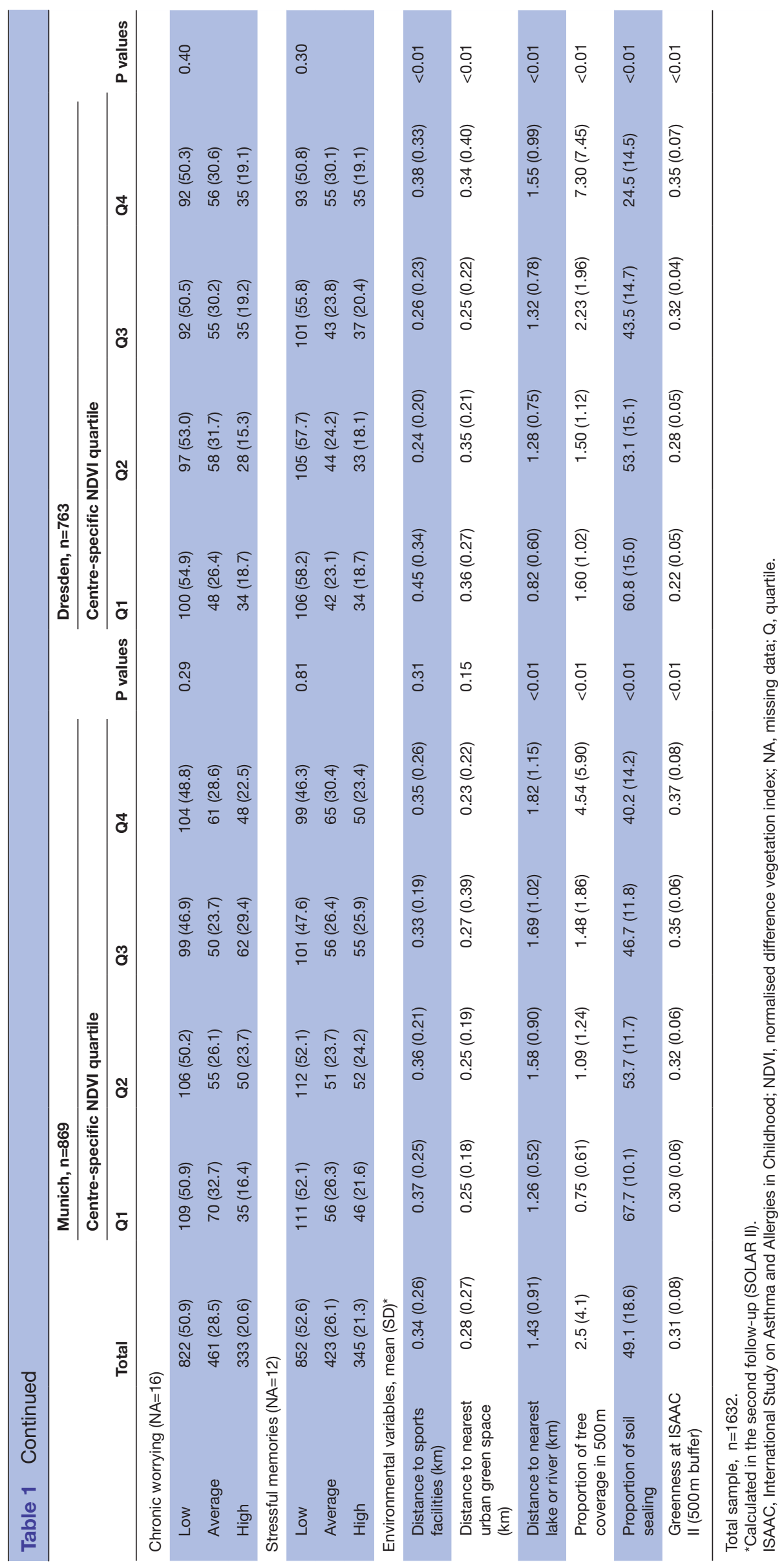

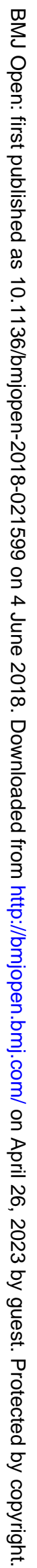


Table 2 Prevalence of job-related chronic stress outcomes by city-specific NDVI quartile in SOLAR I and SOLAR II

\begin{tabular}{|c|c|c|c|c|c|c|c|}
\hline \multicolumn{4}{|c|}{ Munich, $n=869$} & \multicolumn{4}{|c|}{ Dresden, $\mathrm{n}=763$} \\
\hline \multicolumn{4}{|c|}{ Centre-specific NDVI quartile } & \multicolumn{4}{|c|}{ Centre-specific NDVI quartile } \\
\hline Q1 & Q2 & Q3 & Q4 & Q1 & Q2 & Q3 & Q4 \\
\hline
\end{tabular}

SOLAR I

Work discontent $(\mathrm{NA}=14)$

\begin{tabular}{|c|c|c|c|c|c|c|c|c|}
\hline Low & $103(48.4)$ & $108(50.9)$ & $108(50.7)$ & $102(48.1)$ & $111(61.0)$ & 95 (52.2) & $100(55.2)$ & $103(56.3)$ \\
\hline Average & $56(26.3)$ & $60(28.3)$ & $62(29.1)$ & $69(32.5)$ & $46(25.3)$ & 57 (31.3) & 55 (30.4) & $51(27.9)$ \\
\hline High & $54(25.4)$ & $44(20.8)$ & $43(20.2)$ & $41(19.3)$ & $25(13.7)$ & $30(16.5)$ & $26(14.4)$ & $29(15.8)$ \\
\hline \multicolumn{9}{|c|}{ Work overload $(\mathrm{NA}=13)$} \\
\hline Low & $116(55.8)$ & $114(53.5)$ & $125(58.7)$ & $118(55.4)$ & $104(57.1)$ & $97(52.7)$ & $102(56.0)$ & $92(50.5)$ \\
\hline Average & $56(26.9)$ & $63(29.6)$ & $53(24.9)$ & $55(25.8)$ & $50(27.5)$ & $54(29.3)$ & $54(29.7)$ & $60(33.0)$ \\
\hline High & $36(17.3)$ & $36(16.9)$ & $35(16.4)$ & $40(18.8)$ & $28(15.4)$ & $33(17.9)$ & $26(14.3)$ & $30(16.5)$ \\
\hline \multicolumn{9}{|l|}{ SOLAR II } \\
\hline \multicolumn{9}{|c|}{ Work discontent $(N A=14)$} \\
\hline Low & $126(59.4)$ & $135(64.0)$ & $152(71.7)$ & $141(66.8)$ & $108(62.4)$ & $126(72.4)$ & $125(71.4)$ & $127(72.2)$ \\
\hline Average & 47 (22.2) & $43(20.4)$ & $34(16.0)$ & $46(21.8)$ & $40(23.1)$ & $27(15.5)$ & $33(18.9)$ & $30(17.0)$ \\
\hline High & 39 (18.4) & $33(15.6)$ & $26(12.3)$ & $24(11.4)$ & $25(14.5)$ & $21(12.1)$ & $17(9.7)$ & $19(10.8)$ \\
\hline \multicolumn{9}{|c|}{ Work overload $(\mathrm{NA}=13)$} \\
\hline Low & $99(46.7)$ & $110(52.1)$ & $114(53.8)$ & $105(50.0)$ & $90(51.4)$ & $100(56.8)$ & $101(58.0)$ & $98(56.0)$ \\
\hline Average & $59(27.8)$ & $50(23.7)$ & $56(26.4)$ & $64(30.5)$ & $48(27.4)$ & $48(27.3)$ & $38(21.8)$ & $47(26.9)$ \\
\hline High & $54(25.5)$ & $51(24.2)$ & $42(19.8)$ & $41(19.5)$ & $37(21.1)$ & $28(15.9)$ & $35(20.1)$ & $30(17.1)$ \\
\hline
\end{tabular}

Total sample, $\mathrm{n}=1632$.

NA, missing data; NDVI, normalised difference vegetation index; Q, quartile.

students (figure 3A), the OR for work overload was $<1$ for all quartiles compared with the first quartile of NDVI. For workers (figure 3B), no statistically significant difference for work overload and work discontent was seen by NDVI quartiles. Stratifying results for city, results for students followed the same pattern when restricting the analyses for Munich while for work discontent they did not reach the level of statistical significance for students from Dresden. For workers, we did not see any statistically significant associations for participants from Munich while work overload decreased with increasing NDVI quartile in Dresden (figure 3B).

In the mediation analysis, we found a mediated proportion of physical activity on stress of $1.46 \%$ (95\% CI - $10.2 \%$ to $5.6 \%$ ) for work discontent, and a $0.13 \%$ (95\% CI $-0.6 \%$ to $3 \%$ ) for work overload. Unadjusted results were similar to the adjusted ones (see online supplementary table S2). Likewise, complete-case analyses were not different from imputed results (see online supplementary table S3).

\section{DISCUSSION}

In our cohort of young adults in the transition from school to working/university life, we found that more greenness around the place of living corresponds to lower levels of job-related stress. For work discontent, our results suggest a linear, inverse dose-response pattern across quartiles while for work overload we observed a
'J-shape' association. Our results remained robust when controlling for a wide range of confounding factors and with only small differences when stratifying for various subpopulations. These findings thus contribute to an improved understanding of the mental health benefits of green environments, especially in young adults transitioning from school to the university or working life. Our results expand and corroborate the finding of previous studies on the benefits of being exposed to greenness on mental health among different populations. ${ }^{1729} 315455$

Greenness exposure brings benefits on mental health. It could operate through increasing opportunities for physical activity and enhanced access to recreational and sports facilities. ${ }^{5-58}$ Therefore, we controlled for physical activity and distance to sports facilities which did not change the results. Some researchers suggested that physical activity may act as a mediator between greenness and mental health. ${ }^{6}{ }^{17}$ However, this was not confirmed in our mediation analysis. Therefore, we hypothesise that the described associations between greenness and stress might be attributed to mechanisms beyond physical activity, which is in line with other studies. ${ }^{1854}$

In our study, higher exposure to NDVI levels was inversely related to reporting stress at school, university or workplace, indicating that a favourable environment is an essential resource for recreation and recovery, setting off or balancing out stress related to school, 

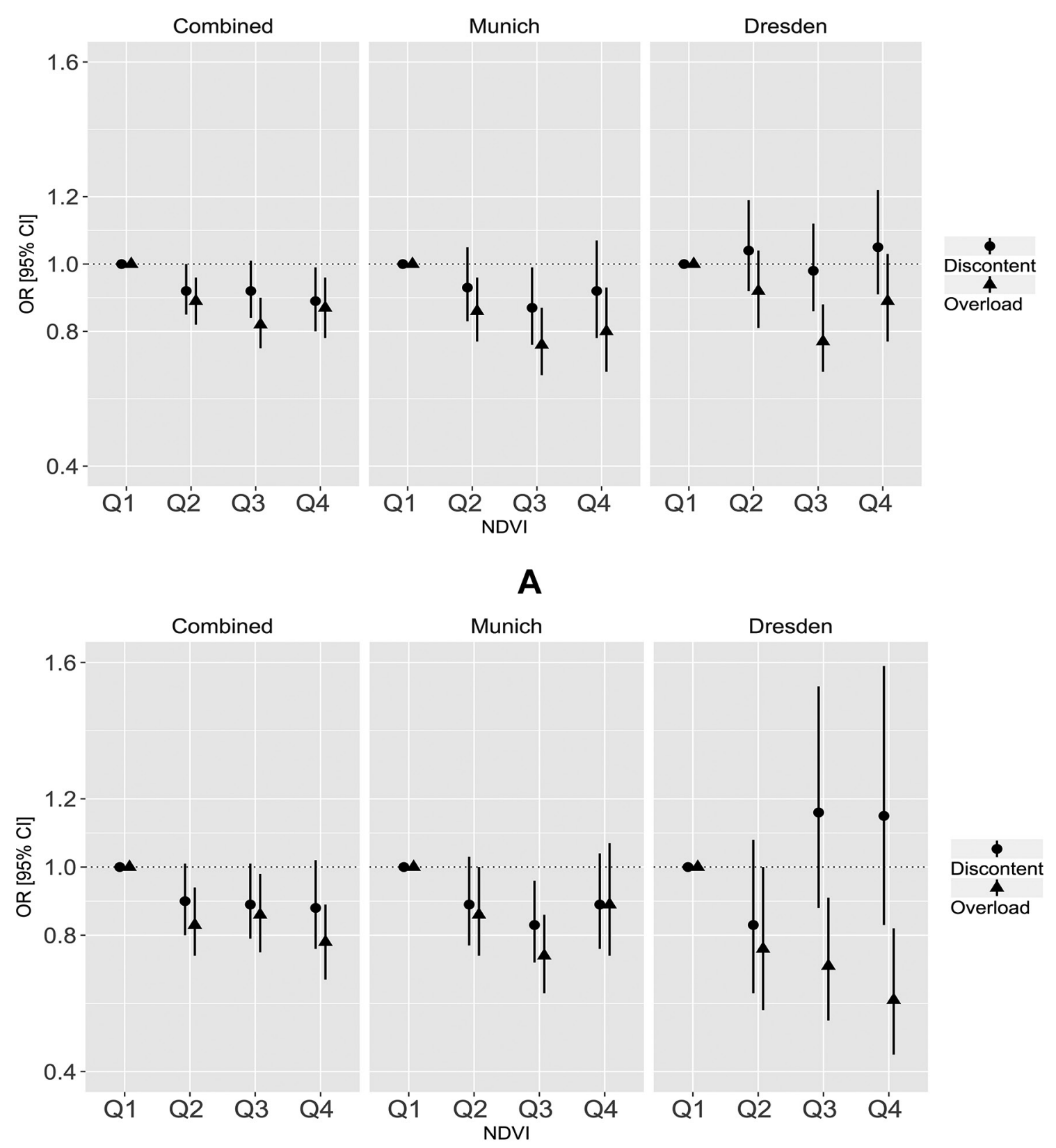

B

Figure 2 City-specific associations between greenness in a $500 \mathrm{~m}$ buffer and work discontent and work overload. Ordinal generalised estimating equation models adjusted for sex, having children, physical activity, education, current status, type of job, psychological variables and environmental variables using complete cases in selected subpopulations: (A) complete cases for the combined population ( $n=1430)$, Munich $(n=779)$ and Dresden $(n=651)$. (B) Complete cases that never moved in the combined population ( $n=629)$, Munich $(n=443)$ and Dresden $(n=186)$. NDVI, normalised difference vegetation index; $Q$, quartile.

university or workplace. The association remained stable when adjusting for type of job/being a student/ being employed so that such potential differences do not explain the observed associations. Differences in the estimated associations between Munich and Dresden may result from different distributions of other factors, like socioeconomic status among both cities, which could affect the susceptibility to greenness exposure and job-related chronic stress. ${ }^{17} 3959$

The 'J-shape' observed for work overload in our study was also seen in an Australian life-course study using
GHQ-12 as a mental health outcome. ${ }^{31}$ We believe that participants in our cohort who were living in the highest greenness quartile have the most extended commuting times between their homes and place of study or work. Commuting plus work/studying may result in increased mental burden measured by work overload. Unfortunately, we did not ask participants for their commuting times. Future studies on this subject should include commuting times as a potential confounder. As suggested by other authors, ${ }^{18} 29305860$ we included environmental variables such as tree coverage, distance to sports facilities, 


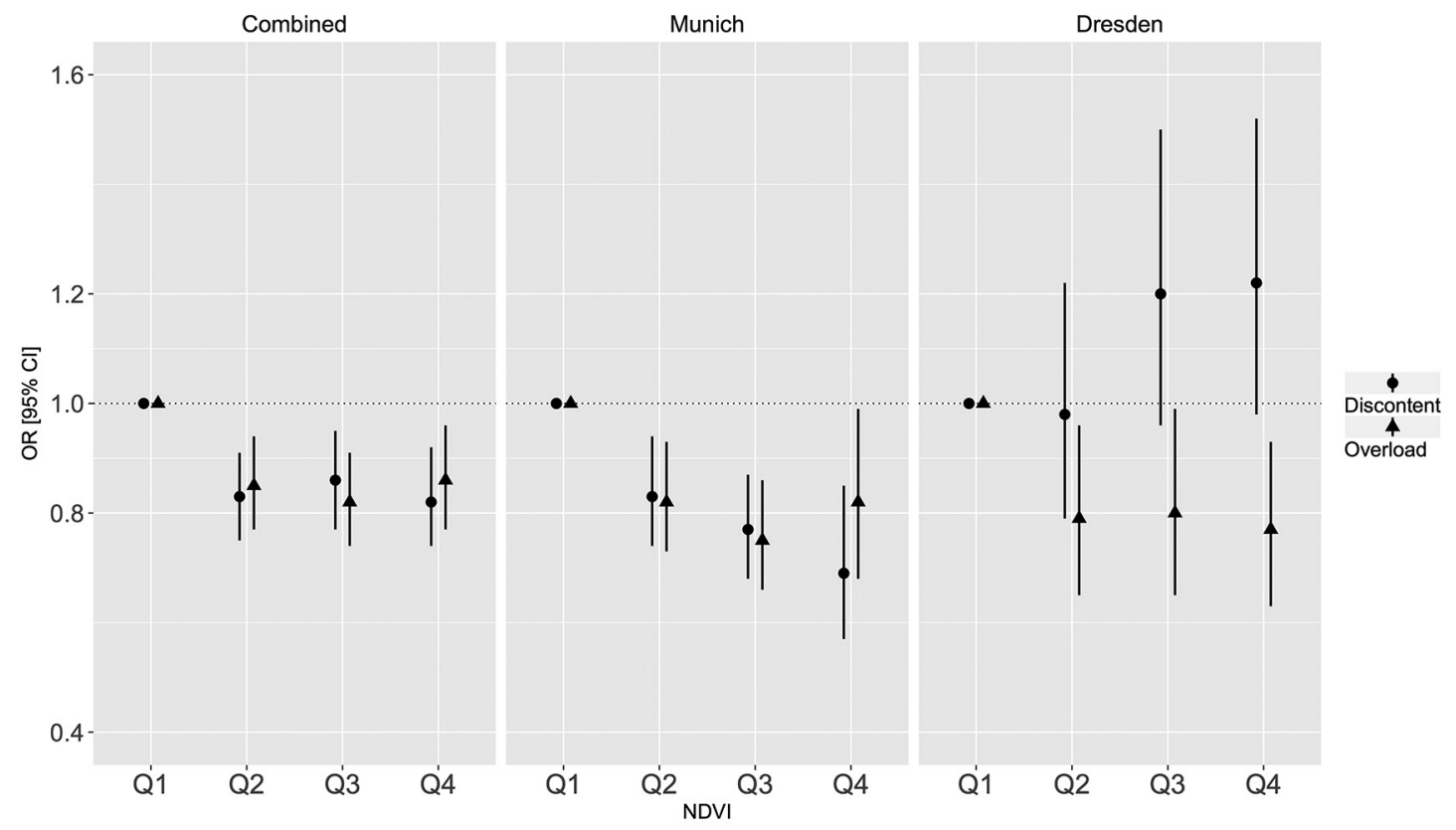

A
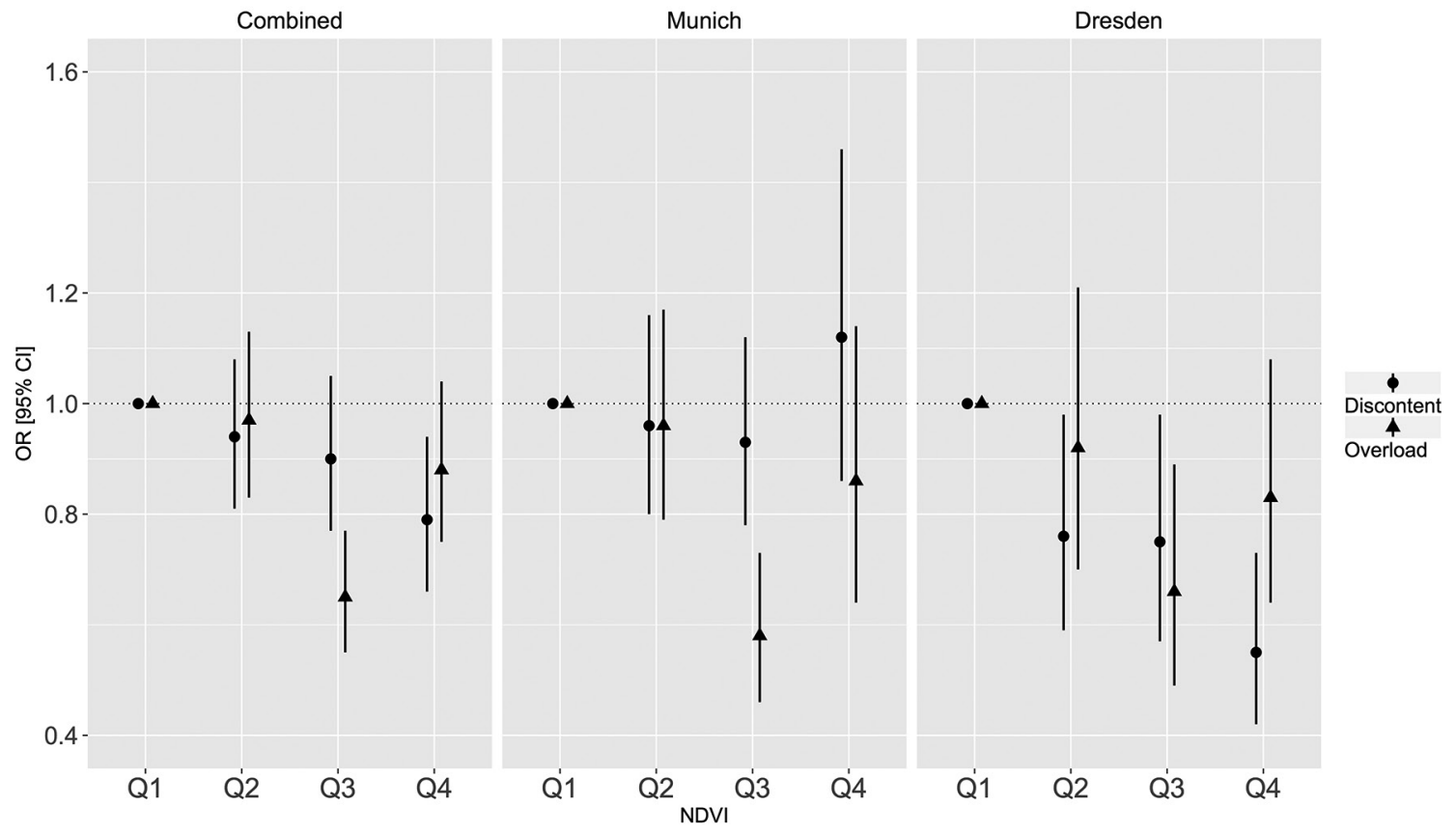

B

Figure 3 City-specific associations between greenness in a $500 \mathrm{~m}$ buffer and work discontent and work overload. Ordinal generalised estimating equation models adjusted for sex, having children, physical activity, education, current status, type of job, psychological variables and environmental variables using complete cases in selected subpopulations: $(A)$ complete cases students only for the combined population $(n=845)$, Munich $(n=463)$ and Dresden $(n=382)$. (B) Complete cases workers only in the combined population $(n=670)$, Munich $(n=359)$ and Dresden $(n=311)$. NDVI, normalised difference vegetation index; $\mathrm{Q}$, quartile.

distance to rivers, etc as potential confounders. However, removing those from the adjusted models did not change the results (data not shown).

Among the strengths of our study is its prospective design, which allows to differentiate the temporal sequence between the exposure to greenness and job-related chronic stress. Our questionnaire focused on asthma and allergies so that participants were not aware of the hypotheses of the current paper. Therefore, we expect differential misclassification of the outcomes to be limited. Standardised, objective and blinded assessments of greenness at each follow-up point, from good satellite 
resolution images are further strengths of our study. Using NDVI as a proxy for exposure to green spaces accounts for all kinds of vegetation, and it can promote greener landscape views and leisure activities, which has shown stress recovering benefits in workers. ${ }^{132} 286$

Among the limitations of our study are the use of satellite images for the NDVI calculations, which were not temporally aligned with the SOLAR I surveys. Nevertheless, we expected spatial greenness to remain stable over several years. ${ }^{58}$ We could not measure exposure to greenness at work because for ethical issues we could not assess the address of the workplace. This made it also impossible to calculate the commuting greenspace of participants. The shortcomings of our study are common, and almost no study in the field has obtained information other than the residential address for greenspace assessment. ${ }^{6061} \mathrm{~A}$ distinctive feature of our study compared with similar ones is that job-related stress was assessed using a validated scale, instead of using general stress and mental health. Residential greenspaces could improve coping mechanisms to job-related chronic stress in different ways, through viewing, physical activity and social interaction. ${ }^{12}{ }^{18}$ Inclusion of additional sources of greenness deserves more attention in future studies on greenness and job-related chronic stress. Our data draw on self-reports of job-related chronic stress, which may be biased by personality or other reporting bias. Moreover, we did not consider whether the participants answered during or after the exam period. Nevertheless, in SOLAR I, participants received the questionnaires between August 2002 and January 2003, which is a period without a high academic load in Germany. In SOLAR II, we sent the questionnaires between August 2007 and November 2008, this means, over a more than a 1 year period. Therefore, SOLAR II also included periods of higher academic load for students. We expected random fluctuations in stress measurement in general, but we do not believe that our results were influenced by this non-differential misclassification because our instrument measures chronic stress rather than study load or workload. ${ }^{33}$ Job-related chronic stress may be influenced by several personal, social and cultural characteristics. Accordingly, we adjusted all estimates for a set of predefined variables such as sex, education, having children and non-job-related chronic stress measurements. In our study, we did not collect contextual data such as ethnic background, cultural conceptions and social cohesion due to legal and logistical reasons. Those suffering from job-related stress at follow-up might have been less likely to participate. However, we do not assume that this depended on our exposure, so potential selection bias should be limited.

\section{CONCLUSION}

Our findings suggest that residential green spaces, measured using the vegetation index, is inversely associated with job-related chronic stress in German young adults transitioning from school to university or working life. Further studies on this topic could further contribute to improve urban planning or to develop recommendations for health promotion through favourable living and working spaces.

\section{Author affiliations}

${ }^{1}$ Occupational and Environmental Epidemiology and NetTeaching Unit, Institute and Outpatient Clinic for Occupational, Social and Environmental Medicine, University

Hospital Munich (LMU), Munich, Germany

${ }^{2}$ Institute for Medical Informatics, Biometry and Epidemiology-IBE, Ludwig-

Maximilians-University Munich (LMU), Munich, Germany

${ }^{3}$ Unit Paediatric Environmental Epidemiology, Institute and Outpatient Clinic for

Occupational, Social and Environmental Medicine University Hospital Munich (LMU),

Munich, Germany

${ }^{4}$ Comprehensive Pneumology Center Munich (CPC-M), German Center for Lung

Research (DZL), Munich, Germany

${ }^{5}$ Institute of Epidemiology I, Helmholtz Zentrum München—German Research Center for Environmental Health, Munich, Germany

${ }^{6}$ Institute of Epidemiology and Medical Biometry, Ulm University, Ulm, Germany

${ }^{7}$ Institute and Outpatient Clinic for Occupational, Social and Environmental

Medicine, University Hospital Munich (LMU), Munich, Germany

${ }^{8}$ Max Planck Institute for Empirical Aesthetics, Frankfurt am Main, Germany

${ }^{9}$ Department of Pediatrics and Adolescent Medicine, University Hospital Carl Gustav

Carus Dresden Technical University Dresden, Dresden, Germany

${ }^{10} \mathrm{Dr}$ von Hauner Children's Hospital, University Hospital Munich (LMU), Munich, Germany

${ }^{11}$ Munich Center of Health Sciences, Ludwig-Maximilians-University, Munich, Germany

Acknowledgements The authors would like to thank all study participants, the study team and all the people involved in the study as well as Daloha RodríguezMolina for her continuous help in the draft of this manuscript.

Contributors $\mathrm{RH}$ was responsible for data analysis and drafting the manuscript. $\mathrm{RH}, \mathrm{UB}, \mathrm{KR}$, and JGer contributed to the data analysis plan. CV, JG and KR are principal investigators of SOLAR (Study on Occupational Allergy Risks). DN, EvM and JG contributed to the planning and conception of the study and manuscript suggestions. IM and JH contributed to the exposure assessment, data analysis and manuscript revision. WS conceived the TICS scale and contributed to the study conception, data interpretation and manuscript suggestions. RH, DW, MW, GW and KR were involved in data interpretation and drafting the paper. All authors critically appraised and approved the final manuscript.

Funding RH received a doctoral scholarship from the Colombian Administrative Department of Science, Technology and Innovation (COLCIENCIAS) (No. 646). The SOLAR study was supported by the Federal Institute for Occupational Safety and Health (BauA), the Federal Ministry of Labour and Social Affairs (BMAS) and the Munich Center for Health Sciences (Ludwig-Maximilians-University).

Competing interests None declared.

Patient consent Obtained.

Ethics approval This study received ethical clearance from the Ethical Committee of the Medical Faculty of the University of Dresden (Dresden, Germany), the Ethical Committee of the Bavarian Chamber of Physicians (Munich, Germany) (EK 38022007) and by the Ethical Committee of the University of Ulm (Ulm, Germany).

Provenance and peer review Not commissioned; externally peer reviewed.

Data sharing statement № additional data are available.

Open Access This is an Open Access article distributed in accordance with the Creative Commons Attribution Non Commercial (CC BY-NC 4.0) license, which permits others to distribute, remix, adapt, build upon this work non-commercially, and license their derivative works on different terms, provided the original work is properly cited and the use is non-commercial. See: http://creativecommons.org/ licenses/by-nc/4.0/

(C) Article author(s) (or their employer(s) unless otherwise stated in the text of the article) 2018. All rights reserved. No commercial use is permitted unless otherwise expressly granted. 


\section{REFERENCES}

1. Grupp H, Köenig HH, Konnopka A. Cost measurement of mental disorders in Germany. J Ment Health Policy Econ 2014;17:3-8.

2. Nations U. World Urbanization Prospects: The 2014 Revision, Highlights. Population Division, United Nations: Department of Economic and Social Affairs, 2014.

3. Miles R, Coutts C, Mohamadi A. Neighborhood urban form, social environment, and depression. J Urban Health 2012;89:1-18.

4. Vlahov D, Galea S. Urbanization, urbanicity, and health. J Urban Health 2002;79:1S-12.

5. Srivastava K. Urbanization and mental health. Ind Psychiatry J 2009;18:75

6. Erdem Ö, Van Lenthe FJ, Prins RG, et al. Socioeconomic Inequalities in Psychological Distress among Urban Adults: The Moderating Role of Neighborhood Social Cohesion. PLoS One 2016;11:e0157119.

7. Trautmann S, Rehm J, Wittchen Hans-Ulrich, Wittchen $\mathrm{HU}$. The economic costs of mental disorders. EMBO Rep 2016;17:e201642951:1245-9.

8. Herrera R, Berger U, Genuneit J, et al. Chronic Stress in Young German Adults: Who Is Affected? A Prospective Cohort Study. Int J Environ Res Public Health 2017;14:1325.

9. Rutt RL, Gulsrud NM. Green justice in the city: A new agenda for urban green space research in Europe. Urban For Urban Green 2016;19:123-7.

10. Gascon M, Triguero-Mas M, Martínez D, et al. Mental health benefits of long-term exposure to residential green and blue spaces: a systematic review. Int J Environ Res Public Health 2015;12:4354-79.

11. James P, Banay RF, Hart JE, et al. A Review of the Health Benefits of Greenness. Curr Epidemiol Rep 2015;2:131-42.

12. Hartig T, Mitchell R, de Vries S, et al. Nature and health. Annu Rev Public Health 2014;35:207-28.

13. Ochodo C, Ndetei DM, Moturi WN, et al. External built residential environment characteristics that affect mental health of adults. $J$ Urban Health 2014;91:908-27.

14. Wolch JR, Byrne J, Newell JP. Urban green space, public health, and environmental justice: The challenge of making cities 'just green enough'. Landsc Urban Plan 2014;125:234-44.

15. Roe JJ, Thompson CW, Aspinall PA, et al. Green space and stress: evidence from cortisol measures in deprived urban communities. Int J Environ Res Public Health 2013;10:4086-103.

16. Lee AC, Maheswaran R. The health benefits of urban green spaces: a review of the evidence. J Public Health 2011;33:212-22.

17. Maas J, Verheij RA, Groenewegen PP, et al. Green space, urbanity, and health: how strong is the relation? J Epidemiol Community Health 2006;60:587-92.

18. Triguero-Mas M, Dadvand $\mathrm{P}$, Cirach $\mathrm{M}$, et al. Natural outdoor environments and mental and physical health: relationships and mechanisms. Environ Int 2015;77:35-41.

19. Akpinar A. How is high school greenness related to students' restoration and health? Urban For Urban Green 2016;16:1-8.

20. Herzog TR, Maguire $P$, Nebel MB, et al. Assessing the restorative components of environments. J Environ Psychol 2003;23:159 -70.

21. Ulrich RS, Simons RF, Losito BD, et al. Stress recovery during exposure to natural and urban environments. J Environ Psycho 1991;11:201-30.

22. Roe JJ, Aspinall PA. Adolescents' daily activities and the restorative niches that support them. Int J Environ Res Public Health 2012;9:3227-44.

23. Korpela K, De Bloom J, Kinnunen U. From restorative environments to restoration in work. Intelligent Buildings International 2015;7:215-23.

24. Sop Shin $\mathbf{W}$. The influence of forest view through a window on job satisfaction and job stress. Scandinavian Journal of Forest Research 2007;22:248-53.

25. Leather P, Pyrgas M, Beale D, et al. Windows in the workplace: Sunlight, view, and occupational stress. Environment and Behavior 1998;30:739-62.

26. Li D, Sullivan WC. Impact of views to school landscapes on recovery from stress and mental fatigue. Landsc Urban Plan 2016;148:149-58.

27. Lottrup L, Grahn P, Stigsdotter UK. Workplace greenery and perceived level of stress: Benefits of access to a green outdoor environment at the workplace. Landsc Urban Plan 2013;110:5-11.

28. Dravigne A, Waliczek TM, Lineberger R, et al. The effect of live plants and window views of green spaces on employee perceptions of job satisfaction. HortScience 2008;43:183-7.

29. Colley K, Brown C, Montarzino A. Understanding Knowledge Workers' Interactions With Workplace Greenspace: Open Space Use and Restoration Experiences at Urban-Fringe Business Sites. Environment and Behavior 2017;49:314-38.

30. Gong Y, Palmer S, Gallacher J, et al. A systematic review of the relationship between objective measurements of the urban environment and psychological distress. Environ Int 2016:96:48-57.

31. Astell-Burt T, Mitchell R, Hartig T. The association between green space and mental health varies across the lifecourse. A longitudinal study. J Epidemiol Community Health 2014;68:578-83.

32. Petrowski K, Paul S, Albani C, et al. Factor structure and psychometric properties of the trier inventory for chronic stress (TICS) in a representative German sample. BMC Med Res Methodol 2012;12:42

33. Schulz P, Schlotz W. Trier Inventory for the Assessment of Chronic Stress (TICS): Scale construction, statistical testing, and validation of the scale work overload. Diagnostica 1999.

34. Heinrich S, Peters A, Kellberger J, et al. Study on occupational allergy risks (SOLAR II) in Germany: design and methods. BMC Public Health 2011;11:298.

35. Weiland SK, Björkstén B, Brunekreef B, et al. Phase II of the International Study of Asthma and Allergies in Childhood (ISAAC II): rationale and methods. Eur Respir J 2004;24:406-12.

36. Hapke U, Maske UE, Scheidt-Nave C, et al. [Chronic stress among adults in Germany: results of the German Health Interview and Examination Survey for Adults (DEGS1)]. Bundesgesundheitsblatt Gesundheitsforschung Gesundheitsschutz 2013;56(5-6):749-54.

37 Solano R, Didan K, Jacobson A, et al. MODIS vegetation index user's guide (MOD13 series). The University of Arizona: Vegetation Index and Phenology Lab, 2010:1-38.

38. James P, Berrigan D, Hart JE, et al. Effects of buffer size and shape on associations between the built environment and energy balance. Health Place 2014;27:162-70.

39. Casey J, James P, Rudolph K, et al. Greenness and Birth Outcomes in a Range of Pennsylvania Communities. Int $J$ Environ Res Public Health 2016;13:311.

40. Organization WH. Global recommendations on physical activity for health, 2010

41. Wolf C. The ISCO-88 International Standard Classification of Occupations in Cross-National Survey Research. Bulletin of Sociological Methodology/Bulletin de Méthodologie Sociologique 1997;54:23-40.

42. Panagos $\mathrm{P}$, Van Liedekerke $\mathrm{M}$, Jones $\mathrm{A}$, et al. European Soil Data Centre: Response to European policy support and public data requirements. Land use policy 2012;29:329-38.

43. Gidlow CJ, Jones MV, Hurst G, et al. Where to put your best foot forward: Psycho-physiological responses to walking in natural and urban environments. J Environ Psychol 2016;45:22-9.

44. Markevych I, Fuertes E, Tiesler CM, et al. Surrounding greenness and birth weight: results from the GINIplus and LISAplus birth cohorts in Munich. Health Place 2014;26:39-46.

45. Jiang B, Chang C-Y, Sullivan WC. A dose of nature: Tree cover, stress reduction, and gender differences. Landsc Urban Plan 2014;132:26-36.

46. Touloumis A, Agresti A, Kateri M. GEE for multinomial responses using a local odds ratios parameterization. Biometrics 2013;69:633-40.

47. Hubbard AE, Ahern J, Fleischer NL, et al. To GEE or not to GEE: comparing population average and mixed models for estimating the associations between neighborhood risk factors and health. Epidemiology 2010;21:467-74.

48. Zorn CJW. Generalized Estimating Equation Models for Correlated Data: A Review with Applications. Am J Pol Sci 2001;45:470-90.

49. Schluchter MD. Flexible Approaches to Computing Mediated Effects in Generalized Linear Models: Generalized Estimating Equations and Bootstrapping. Multivariate Behav Res 2008;43:268-88.

50 Harel O, Mitchell EM, Perkins NJ, et al. Multiple Imputation for Incomplete Data in Epidemiologic Studies. American Journal of Epidemiology 2017.

51. White IR, Royston P, Wood AM. Multiple imputation using chained equations: Issues and guidance for practice. Stat Med 2011;30:377-99.

52. Rubin DB. Inference and missing data. Biometrika 1976;63:581-92.

53. Team RC. R: A language and environment for statistical computing. Vienna, Austria: R Foundation for Statistical Computing, 2014.

54. Markevych I, Tiesler CM, Fuertes E, et al. Access to urban green spaces and behavioural problems in children: Results from the GINIplus and LISAplus studies. Environ Int 2014;71:29-35.

55. Burton JP, Hoobler JM, Scheuer ML. Supervisor workplace stress and abusive supervision: The buffering effect of exercise. J Bus Psychol 2012;27:271-9.

56. Trenberth L, Dewe P, Walkey F. Leisure and its role as a strategy for coping with work stress. Int J Stress Manag 1999;6:89-103.

57. Ohta M, Mizoue T, Mishima N, et al. Effect of the physical activities in leisure time and commuting to work on mental health. J Occup Health 2007:49:46-52. 
58. Markevych I, Smith MP, Jochner S, et al. Neighbourhood and physical activity in German adolescents: GINIplus and LISAplus. Environ Res 2016;147:284-93.

59. van den Berg AE, Maas J, Verheij RA, et al. Green space as a buffer between stressful life events and health. Soc Sci Med 2010;70:1203-10.
60. Amoly E, Dadvand P, Forns J, et al. Green and blue spaces and behavioral development in Barcelona schoolchildren: the BREATHE project. Environ Health Perspect 2014;122:1351.

61. Dadvand P, Nieuwenhuijsen MJ, Esnaola M, et al. Green spaces and cognitive development in primary schoolchildren. Proc Natl Acad Sci U S A 2015;112:7937-42. 